\title{
o-Nitrobenzyl Ester Based Deep UV Resist for KrF Excimer Laser Lithography
}

\author{
Masayuki ENDO, Yoshiyuki TANI, Masaru SASAGO, \\ and Noboru NOMURA \\ Semiconductor Research Center, Matsushita Electric Ind. Co., Ltd., \\ Moriguchi 570, Japan
}

(Received January 4, 1989)

\begin{abstract}
We developed a new positive deep UV resist for $\mathrm{KrF}$ excimer laser lithography, which is an alkaline-dissolution-inhibition type. It is composed of $o$-nitrobenzyl cholate as the dissolution inhibitor, poly ( $p$-vinylphenol) as the alkali-soluble polymer and cyclohexanone as the coating solvent. $0.35 \mu \mathrm{m}$ line-and-space patterns in $1.0 \mu \mathrm{m}$ thickness were successfully fabricated using this new resist. It was found that the new resist still has a large absorbance for the $\mathrm{KrF}$ excimer laser at the resist surface. However, it has superior capability of resolution.

KEY WORDS Deep UV Resist / KrF Excimer Laser / Lithography / oNitrobenzyl Cholate / Poly ( $p$-vinylphenol) /
\end{abstract}

$\mathrm{KrF}(248 \mathrm{~nm})$ excimer laser lithography is a most exciting technology for lower submicron VLSt in recent years. The technology has pattern fabrication ability below $0.5 \mu \mathrm{m} .{ }^{1-4}$

However, the problems of the resists for $\mathrm{KrF}$ excimer laser lithography have not been resolved yet. A conventional naphthoquinonediazide-novolac resin type deep UV resist has good sensitivity for $\mathrm{KrF}$ excimer laser, while the pattern profile of the resist is degraded because of strong photoabsorption to the $\mathrm{KrF}$ excimer laser. ${ }^{5}$

$\mathrm{We}^{6}$ and Wolf et al. ${ }^{7}$ reported the evaluation of various types of resists. There were no suitable and excellent resists for $\mathrm{KrF}$ excimer laser lithography.

As one approach for the improvement of the resolution and pattern profile, we developed a new alkaline-dissolution-inhibition type positive deep UV resist. It is composed of an $o$ nitrobenzyl cholate as the alkaline dissolution inhibitor and poly( $p$-vinylphenol) as the alkali-soluble polymer. ${ }^{8}$

$o$-Nitrobenzyl cholate has already been re- ported as an alkaline dissolution inhibitor for poly(methyl methacrylate-co-methacrylic acid). ${ }^{9.10}$ The characteristics of their blended resist were discussed and excellent results for deep UV printing were obtained. Its applications to $\mathrm{KrF}$ excimer laser lithography, however, were not good. It was reported that high degree of thinning during development was observed and all high resolution patterns of size $\leqslant 1.0 \mu \mathrm{m}$ were lost. ${ }^{7}$

We improved the resolution capability of such an $o$-nitrobenzyl ester based deep UV resist to $\mathrm{KrF}$ excimer laser using poly $(p$ vinylphenol) as a non-swelling alkali-soluble polymer, ${ }^{11}$ which is relatively transparent in a deep UV region. ${ }^{12}$ Material characterizations and lithographic evaluations of this new resist are discussed in this paper.

\section{EXPERIMENTAL}

\section{Materials}

The new positive deep UV resist consists of an o-nitrobenzyl cholate (Figure 1a) as the 


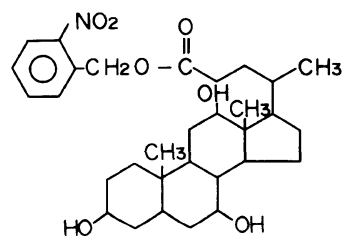

(a)

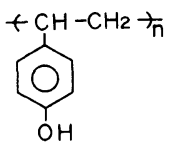

(b)

Figure 1. The composition of the new resist: (a) $o$ nitrobenzyl cholate; (b) poly( $p$-vinylphenol).

alkaline dissolution inhibitor, poly $(p$-vinylphenol) (Figure 1b) as the alkali-soluble polymer and cyclohexanone as the coating solvent.

$o$-Nitrobenzyl cholate was prepared by standard synthetic techniques. ${ }^{13,14} \operatorname{Poly}(p$ vinylphenol) $\left(M_{w}\right.$.10000) was obtained from Maruzen Oil Co..

The weight content ratio of the resist was $1: 5: 15$ for $o$-nitrobenzyl cholate/poly $(p$ vinylphenol)/cyclohexanone. The optimization of the composition was performed so that the sensitivity would become maximal.

The UV spectra of the $o$-nitrobenzyl cholate in a quartz cell and the resist film on a quartz substrate were measured with a Shimadzu UV265FS double-beam spectrometer. The FTIR analysis of the film on a silicon substrate was performed with a Shimadzu FT-IR 4000 double-beam spectrometer.

\section{Lithographic Evaluation}

The new resist was spin-coated on a silicon substrate and baked for $30 \mathrm{~min}$ at $140^{\circ} \mathrm{C}$ in a convection oven. The film thickness was $1.0 \mu \mathrm{m}$. The exposure was done with a $5 \mathrm{X} \mathrm{KrF}$ excimer laser stepper (Numerical Aperture 0.36) we manufactured..$^{15}$ After exposure, the resist film was developed with a $60 \mathrm{~s}$ immersion in tetramethylammonium hydroxide (TMAH) solution.
Sensitivity was defined as the exposure energy necessary to result in complete removal of the resist in the exposed areas with the minimum resist loss in the unexposed regions. Contrast values were assessed by measuring the slope of the linear portion of the crude obtained by plotting the thickness of the relief image as a function of the logarithm of the exposure energy. ${ }^{16}$ The film thickness was measured with a Nanospec AFT film thickness monitor (Nanometrics).

The resist pattern profiles were evaluated using a JEOL JSM-T200 scanning electron microscope.

\section{RESULTS AND DISCUSSION}

\section{Spectroscopic Characteristics}

Figures 2 and 3 show the UV spectra of $o$ nitrobenzyl cholate and $1.0 \mu \mathrm{m}$-thick new resist before and after $\mathrm{KrF}$ excimer laser irradiation of $4.0 \mathrm{~J} \mathrm{~cm}^{-2}$, respectively. $o$ Nitrobenzyl cholate bleached only a little and the resist did not bleach at $248 \mathrm{~nm}$. However, the transmittance of $47.6 \%$ of the resist was much higher than that of conventional naphthoquinonediazide-novolac resin type deep UV resist, MP2400 (Shipley) $(9.3 \%) .{ }^{17}$

Figure 4 shows the FT-IR characteristics of the new resist in $1.0 \mu \mathrm{m}$ thickness before and after $\mathrm{KrF}$ excimer laser irradiation of 4.0 $\mathrm{J} \mathrm{cm}^{-2}$, respectively. After $\mathrm{KrF}$ excimer laser irradiation, the bond attributed to the nitro group $\left(1518 \mathrm{~cm}^{-1}\right)$ was reduced while that of the nitroso group $\left(1503 \mathrm{~cm}^{-1}\right)$ increased.

These results suggest that the following reaction occurred with such an $o$-nitrobenzyl ester based positive resist. That is, upon irradiation with $\mathrm{KrF}$ excimer laser, the $o$ nitrobenzyl ester undergoes a rearrangement to generate $o$-nitrosobenzaldehyde plus a carboxylic acid. ${ }^{10}$ In this manner, an alkaliinsoluble ester becomes soluble in alkaline developers so that the ability of alkalinedissolution-inhibition of the ester is weakened. Consequently, a positive-tone resist pattern is 


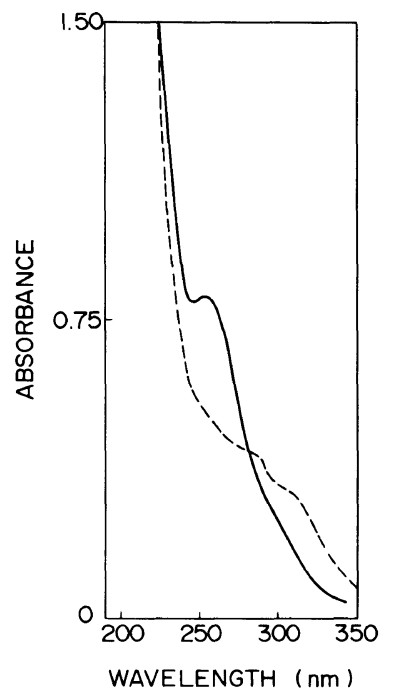

Figure 2. UV spectra of ortho-nitrobenzyl cholate: $(-)$, before $\mathrm{KrF}$ excimer laser irradiation; (----), after $\mathrm{KrF}$ excimer laser irradiation. The irradiation energy, $4.0 \mathrm{~J} \mathrm{~cm}^{-2}$.

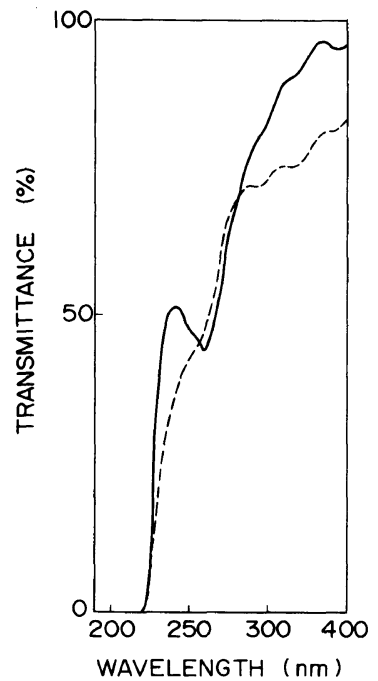

Figure 3. UV spectra of the new resist in $1.0 \mu \mathrm{m}$ thickness: (-), before $\mathrm{KrF}$ excimer laser irradiation; (--), after $\mathrm{KrF}$ excimer laser irradiation. The irradiation energy, $4.0 \mathrm{~J} \mathrm{~cm}^{-2}$.

fabricated. It became clear that such a reaction mechanism of the resist for $\mathrm{KrF}$ excimer laser irradiation is the same as for deep UV irradiation. ${ }^{10}$

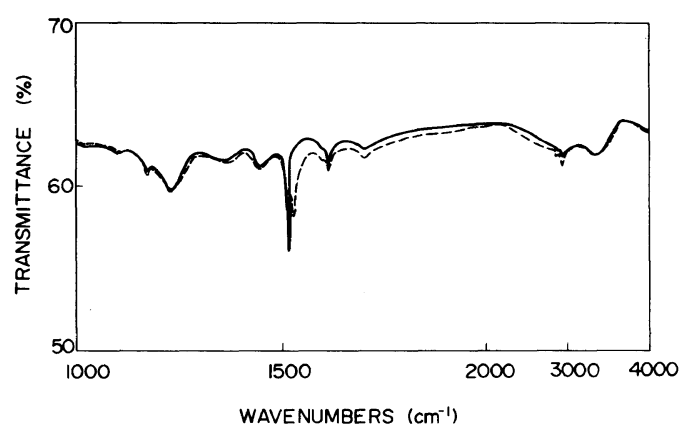

Figure 4. FT-IR characteristics of the new resist in $1.0 \mu \mathrm{m}$ thickness: (-), before $\mathrm{KrF}$ excimer laser irradiation; (--- ), after $\mathrm{KrF}$ excimer laser irradiation. The irradiation energy, $4.0 \mathrm{~J} \mathrm{~cm}^{-2}$.

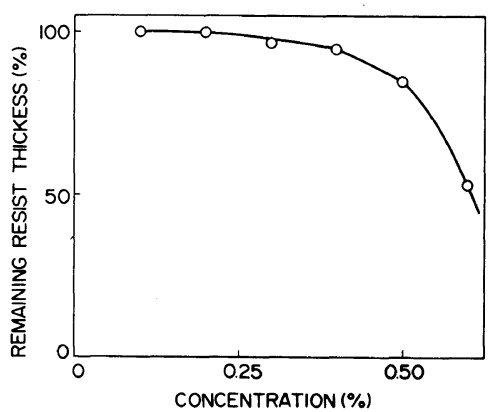

Figure 5. The relationship between the weight concentration of tetramethylammonium hydroxide and the remaining resist thickness in unexposed regions.

\section{Optimization of the Developer Concentration}

Because of the high solubility of the poly $(p$ vinylphenol) to the alkaline solution, the alkaline concentration of the developer of TMAH solution for the present resist must be carefully optimized.

Figure 5 shows the relationship of the weight concentration of TMAH and the remaining resist thickness in unexposed regions after $60 \mathrm{~s}$ immersion into each TMAH solution. There was observed much loss of resist thickness when the concentration of TMAH solution exceeded $0.50 \%$.

The weight concentration of TMAH versus the sensitivity of the $1.0 \mu \mathrm{m}$-thick resist is shown in Figure 6. It was found that the 


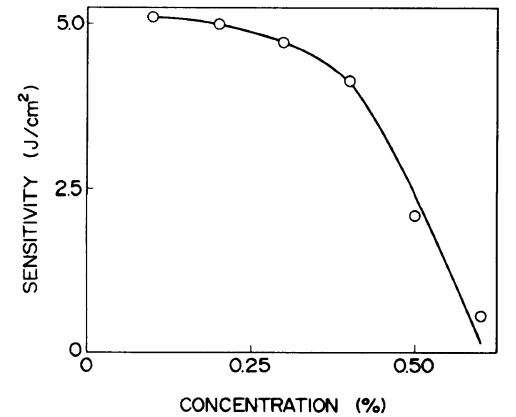

Figure 6. The relationship between the weight concentration of tetramethylammonium hydroxide and the sensitivity of the resist in $1.0 \mu \mathrm{m}$ thickness.

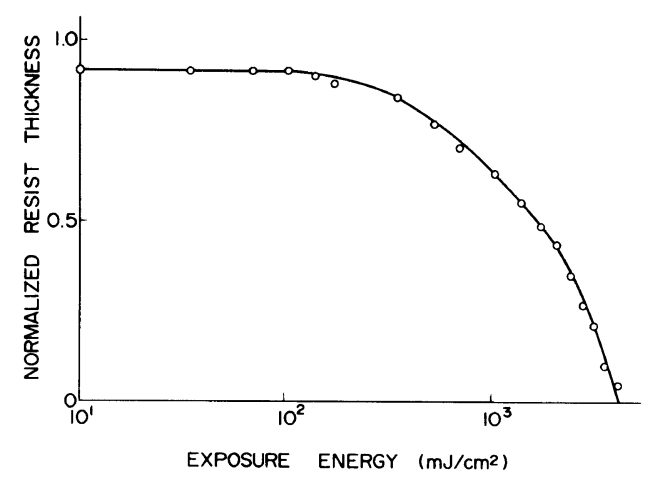

Figure 7. Sensitivity characteristics of the new resist in $1.0 \mu \mathrm{m}$ thickness.

sensitivity became much less when the concentration of TMAH became less than $0.40 \%$.

From these results, it was concluded that the $0.45 \%$ concentration of TMAH solution would be most suitable for $\mathrm{KrF}$ excimer laser lithography. This developer concentration was subjected to lithographic evaluation.

\section{Sensitivity Characteristics and Pattern Res- olution}

Figure 7 shows the sensitivity characteristics of the resist in $1.0 \mu \mathrm{m}$ thickness. The contrast (1.69) was excellent although the sensitivity was not so good $\left(3.0 \mathrm{~J} \mathrm{~cm}^{-2}\right)$.

$0.35 \mu \mathrm{m}$ line-and-space patterns of the resist in $1.0 \mu \mathrm{m}$ thickness were successfully fabricated (Figure 8). From this figure, it can be seen that loss of resist thickness and degra-

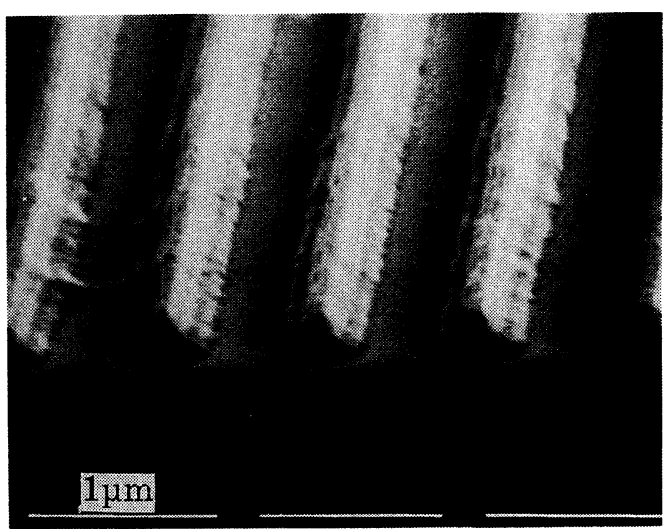

Figure 8. SEM photograph of $0.35 \mu \mathrm{m}$ line-and-space patterns of the new resist in $1.0 \mu \mathrm{m}$ thickness.

dation of the pattern profile occurs in unexposed regions, which is due to a still large absorbance for $\mathrm{KrF}$ excimer laser at the resist surface. However, it has superior capability of resolution. The higher aspect ratio pattern could be attained by adoption of a more transparent polymer for the resist. As also shown in this figure, $o$-nitrobenzyl cholate seems to be a better alkaline dissolution inhibitor for $\operatorname{poly}(p$-vinylphenol) than for poly(methyl methacrylate-co-maleic acid). ${ }^{9.10}$

\section{CONCLUSIONS}

A new positive deep UV resist was developed. It is composed of an $o$-nitrobenzyl cholate as the alkaline dissolution inhibitor, $\operatorname{poly}(p$-vinylphenol) as the alkali-soluble polymer and cyclohexanone as the coating solvent.

We successfully achieved sub-half-micron $(0.35 \mu \mathrm{m})$ patterns in a thick $(1.0 \mu \mathrm{m})$ resist film. The increase of the transmittance of the polymer in the resist is required for improvement of the pattern profile. We are convinced that this $o$-nitrobenzyl ester based positive resist can be effectively used for $\mathrm{KrF}$ excimer laser lithography because of its excellent resolution capability. 


\section{REFERENCES}

1. K. Jain, C. G. Willson, and B. J. Lin, IBM J. Res. Dev., 26, 151 (1982).

2. V. Pol, J. H. Bennewitz, G. C. Escher, M. Feldman, V. A. Firtion, T. E. Jewell, B. E. Wilcomb, and J. T. Clemens, Proc. SPIE, 631, 6 (1986).

3. M. Sasago, M. Endo, Y. Hirai, K. Ogawa, and T. Ishihara, presented at International Electron Devices Meeting, Los Angeles, December 5-8, 1986, p 316.

4. M. Nakase, T. Sato, M. Nonaka, I. Higashikawa, and Y. Horiike, Proc. SPIE, 773, 226 (1987).

5. M. Endo, M. Sasago, Y. Hirai, K. Ogawa, and T. Ishihara, Proc. SPIE, 774, 138 (1987).

6. M. Endo, M. Sasago, H. Nakagawa, Y. Hirai, K. Ogawa, and T. Ishihara, Denshijohotsushin Gakkai Ronbunshi, C, J71-C, 195 (1988).

7. T. M. Wolf, R. L. Hartless, A. Shugard, and G. N. Taylor, J. Vac. Sci. Technol., B5, 396 (1987).

8. M. Endo, M. Sasago, Y. Hirai, K. Ogawa, and T. Ishihara, presented at IUPAC 32nd International Symposium on Macromolecules, Kyoto, August 1 6,1988 , p 540.
9. E. Reichmanis, C. W. Wilkins, Jr, and E. A. Chandross, J. Vac. Sci. Technol., 19, 1338 (1981).

10. E. Reichmanis, C. W. Wilkins, Jr., D. A. Price, and E. A. Chandross, J. Electrochem. Soc., 130, 1433 (1983).

11. T. Iwayanagi, T. Kohashi, S. Nonogaki, T. Matsuzawa, K. Douta, and H. Yanazawa, IEEE Trans. Electron Devices, ED-28, 1306 (1981).

12. C. G. Willson, H. Ito, J. M. J. Fréchet, T. G. Tessier, and F. M. Houlihan, J. Electrochem. Soc., 133, 181 (1986).

13. P. M. Kochergin and K. S. Bushueva, Zh. Obshch. Khim., 32, 3033 (1962).

14. F. Cortese and L. Bauman, J. Am. Chem. Soc., 57, 1393 (1935).

15. H. Nakagawa, M. Sasago, M. Endo, Y. Hirai, K. Ogawa, and T. Ishihara, Proc. SPIE, 922, 400 (1988).

16. L. F. Thompson, Solid State Technol., 17(7), 27 (1974).

17. M. Endo, Y. Tani, M. Sasago, K. Ogawa, and N. Nomura, presented at the 20th (1988 International) Conference on Solid State Devices and Materials, Tokyo, August 20-23, 1988, p 557. 